\title{
Medical therapy versus trabeculectomy in patients with open-angle glaucoma
}

\author{
Tratamento clínico versus trabeculectomia em pacientes com glaucoma de ângulo aberto
}

Behzad Fallahi Motlagh ${ }^{1}$

\begin{abstract}
Purpose: To compare therapeutic outcomes between trabeculectomy and medical therapy in patients with open-angle glaucoma.

Methods: In the present retrospective comparative study, the medical charts of 284 patients (eyes) newly diagnosed with open-angle glaucoma who had received conventional medications $(n=188)$ or undergone fornix-based trabeculectomy $(n=96)$ at a teaching eye hospital were reviewed.

Results: At a mean follow-up of 6.6 years, post-treatment changes in intraocular pressure (IOP), visual field (VF), best spectacle-corrected visual acuity (BSCVA), and number of required drugs were significantly more favorable in the surgical group $(\mathrm{P}<0.001$ for all comparisons). However, the frequency of clinically desirable IOP $(\leq 21 \mathrm{mmHg}$ ) at the endpoint was comparable between the surgical and medical groups ( $87.2 \%$ vs. $82.3 \% ; P=0.26$ ). The rate of conversion to surgical therapy was $34 \%$ in the medical group. A greater baseline requirement for anti-glaucoma drugs (two or more) was the only independent predictor of treatment failure in the present study.

Conclusions: Although more severe cases naturally receive trabeculectomy, the surgical approach had greater efficacy than conventional medical therapy in patients with open-angle glaucoma. An initial requirement for two or more anti-glaucoma drugs may predict failure of medical therapy.
\end{abstract}

Keywords: Glaucoma, open-angle/drug therapy; Glaucoma, open-angle/surgery; Trabeculectomy; Visual acuity

\begin{abstract}
RESUMO
Objetivo: Comparar o resultado terapêutico de trabeculectomia versus terapia médica em pacientes com glaucoma de ângulo aberto.

Método: Neste estudo comparativo retrospectivo, prontuários médicos de 284 pacientes (olhos), de um hospital de ensino oftalmológico, com diagnóstico recente de glaucoma de ângulo aberto que receberam medicamentos convencionais $(n=188)$ ou foram submetidos a trabeculectomia de base fórnice $(n=96)$ foram revisados.

Resultados: Com seguimento médio de 6,6 anos, as mudanças pós-tratamento da pressão intraocular (PIO), campo visual (VF), melhor acuidade visual corrigida por óculos (BSCVA), e o número de medicações necessárias foram significativamente mais favorável ao grupo cirúrgica ( $\mathrm{p}<0,001$ para todas as comparações). No entanto, os grupos foram comparáveis para afrequência de PIO clinicamente desejável ( $\leq 21 \mathrm{mmHg}$ ) na visita final $(87,2 \%$ vs. $82,3 \%$, respectivamente; $\mathrm{p}=0,26)$. A taxa de conversão para 0 tratamento cirúrgico foi de 34\% no grupo médico e a necessidade inicial de mais drogas antiglaucomatosas (2 ou mais) foi o único preditor independente desta conversão.

Conclusões: Embora os casos mais graves de glaucoma sãonaturalmentedesignados o grupo de trabeculectomia, esta abordagem cirúrgica se mostrou mais eficaz do que a terapia médica convencional em pacientes com glaucoma de ângulo aberto. Uma necessidade inicial de 2 ou mais medicações antiglaucomatosas pode prever a falha em terapia médica.
\end{abstract}

Descritores: Glaucoma de ângulo aberto/quimioterapia; Glaucoma de ângulo aberto/cirurgia; Trabeculectomia; Acuidade visual

\section{INTRODUCTION}

Glaucoma is the most common cause of visual impairment and blindness, with an estimated worldwide prevalence of 60 million $n^{(1,2)}$.

The primary target of available standard treatments is intraocular pressure (IOP) because elevated IOP has been shown to contribute to neural cell death in glaucoma ${ }^{(3)}$. In addition, IOP is currently regarded as the only practically modifiable risk factor in glaucoma with consequential benefits in preserving the visual field $(\mathrm{VF})^{(4)}$. Both medical and surgical approaches have demonstrated efficacy in decreasing $1 \mathrm{OP}{ }^{(5)}$. Examples of commonly used medications in treating glaucoma include eye drops, such as beta-adrenergic antagonists and prostaglandin analogs, topical and oral carbonic anhydrase inhibitors, and alpha-adrenergic agonists. On the other hand, trabeculectomy has been considered the surgical method of choice since the late $1960 s^{(5,6)}$.

Previously, several studies have compared therapeutic therapeutic outcomes between medical treatment and trabeculectomy in patients with glaucoma. However, the results of these studies have been inconclusive because of technical limitations, such as short follow-up periods and heterogeneous study groups; in addition, many such studies are very old and outdated ${ }^{(5,7-9)}$. In addition, recent studies have reported the development of newer anti-glaucoma drugs, in addition to the refinement of surgical techniques. Thus, the present study aimed to compare therapeutic outcomes between trabeculectomy and conventional medical therapy in patients with open-angle glaucoma.

\section{METHODS}

In the present retrospective study, the medical records of 284 Azeri patients with newly diagnosed open-angle glaucoma treated at Nikookari teaching eye hospital between 2009 and 2014 were reviewed. The present study was approved by the ethics committee of the Tabriz University of Medical Sciences.

The diagnosis and classification of glaucoma was performed according to previously accepted guidelines ${ }^{(5,10)}$. Only one eye of each patient was used in the present study, including the involved eye in patients with unilateral glaucoma, and the eye with more severe disease in patients with bilateral glaucoma. Accordingly, 96 eyes were assigned to the surgical (trabeculectomy) group, and 188 eyes were assigned to the medical group.
Funding: No specific financial support was available for this study.

Disclosure of potential conflicts of interest: None of the authors have any potential conflict of interest to disclose.

Corresponding author: Behzad Fallahi Motlagh. Nikookari Eye Hospital. Haj Hashem Station, Abbasi Street - Tabriz - Iran - E-mail: bfm1346@yahoo.com

Approved by the following research ethics committee: Tabriz University of Medical Sciences (\# 91.1-6.9). 
The exclusion criteria for the present study were as follows: previous diagnosis of glaucoma (up to 2 weeks before enrollment), history of eye trauma, presence of risk factors for failure of trabeculectomy (age less than 40 years at diagnosis, previous intraocular surgery, and inflammatory, neovascular, traumatic, dysgenetic, or aphakic/pseudophakic types of glaucoma) $)^{(11)}$, any eye surgery during the follow-up period, insufficient data, and insufficient follow-up period. Information for follow-up was obtained from patient charts. In our clinic, all newly diagnosed patients with open-angle glaucoma initially receive medical treatment, including beta blockers or prostaglandin analogues, with further medications added in a step-by-step fashion until the target IOP is achieved. In patients in whom the target $\mathrm{IOP}$ is not achieved by 12 weeks, trabeculectomy without mitomycin-C is performed providing patients are considered to be at low risk of surgical treatment failure. In the present study, all patients in the surgical group underwent fornix-based trabeculectomy without releasable suture, with similar follow-up to other patients.

At the time of admission all patients underwent a set of complete eye examinations, including best spectacle visual acuity measurements using standard Snellen charts, gonioscopy, IOP measurement with a standard applanation tonometer, detailed optic disc examinations, and perimetry. IOP measurements were performed in the morning, with the average of two consecutive readings used in the present study analysis. Perimetry was performed using a Humphrey Field Analyzer (HFA; model II 750, Carl Zeiss Meditec AG, Jena, Germany), with the SITA STANDARD 30-2 threshold strategy employed. The mean deviation (MD) of perimetric indexes was used in all subsequent analyses.
All trabeculectomies had been performed by 3 experienced attendant surgeons, with a target IOP of less than or equal to $21 \mathrm{mmHg}$ considered clinically desirable ${ }^{(6)}$.

\section{Statistical analysis}

SPSS software version 22.0 (IBM, USA) was used for all statistical analyses. A normal distribution of numerical data was confirmed using the Kolmogorov-Smirnov test. Independent samples $t$ test (for comparisons of age, follow-up time, IOP, VF, best spectacle corrected visual acuity (BSCVA), drug number, time of adding further drug(s), and time of operation/reoperation between groups), chi-square test (for comparisons of sex, glaucoma type, need for further drug(s), need for operation/reoperation, and designated IOP between groups), repeated measures analysis (for determining changing trends in mean IOP, VF, BSCVA, and drug number before and after treatment), and a logistic regression model (for detecting possible independent predictors of failure in treatment) were used. Receiver operator characteristic (ROC) curves were used to determine the optimal cut-off point for drug number at baseline in predicting medical failure. P-values of $\leq 0.05$ were considered statistically significant.

\section{RESULTS}

Comparisons of demographic data and study variables before and after treatment between the two medical and surgical groups are presented in table 1. The two groups were comparable in terms of

Table 1. Comparison of study variables between surgical and medical therapies

\begin{tabular}{|c|c|c|c|}
\hline Variable & $\begin{array}{c}\text { Surgical } \\
(n=96)\end{array}$ & $\begin{array}{l}\text { Medical } \\
(n=188)\end{array}$ & P-value \\
\hline Age (year) & $67.38 \pm 8.70(48-85)$ & $69.02 \pm 9.73(40-94)$ & 0.170 \\
\hline \multicolumn{4}{|l|}{ Sex } \\
\hline Male & $70(72.9 \%)$ & $150(79.8 \%)$ & 0.190 \\
\hline Female & $26(27.1 \%)$ & $38(20.2 \%)$ & \\
\hline \multicolumn{4}{|l|}{ Glaucoma type } \\
\hline POAG & $25(26.0 \%)$ & $68(36.2 \%)$ & \\
\hline Follow-up (month) & $80.40 \pm 26.66(51-200)$ & $78.38 \pm 24.81(54-194)$ & 0.530 \\
\hline \multicolumn{4}{|l|}{ IOP (mmHg) } \\
\hline Baseline & $31.71 \pm 12.86(14-860)$ & $24.58 \pm 9.87(10-640)$ & $<0.001^{*}$ \\
\hline Endpoint & $16.42 \pm 8.24(0-450)$ & $16.33 \pm 6.14(7-450)$ & - \\
\hline Endpoint & $-19.42[3.71](-33$ to 2$)$ & $-18.33[6.67](-250$ to 50.2$)$ & - \\
\hline \multicolumn{4}{|l|}{ BSCVA (logMAR) } \\
\hline Baseline & $0.86[0.06](0-1.8)$ & $0.57[0.04](0-1.8)$ & $<0.001^{*}$ \\
\hline Endpoint & $1.13[0.06](0.1-2)$ & $0.76[0.04](0.2-1.9)$ & - \\
\hline \multicolumn{4}{|l|}{ Drug no } \\
\hline Baseline & $2.54 \pm 0.58(1-4)$ & $2.17 \pm 0.71(1-4)$ & $<0.001^{*}$ \\
\hline Endpoint & $1.92 \pm 1.19(0-4)$ & $2.31 \pm 1.00(0-4)$ & - \\
\hline Need for further drugs & $80(83.3 \%)$ & $110(58.5 \%)$ & $<0.001^{*}$ \\
\hline Time of adding further drug(s) (months) & $12.97[1.33](2-65)$ & $13.18[1.23](2-108)$ & 0.910 \\
\hline Need for operation/reoperation & $11(11.5 \%)$ & $64(34 \%)$ & $<0.001^{*}$ \\
\hline Time of operation/reoperation (months) & $29.00[8.86](8-85)$ & $39.00[3.42](9-125)$ & 0.270 \\
\hline
\end{tabular}


sex, age, and follow-up time. In contrast, the frequency of pigmentary subtype of glaucoma (PIG), and mean IOP, BSCVA, and number of drugs at baseline were significantly higher in the surgical group. The mean pretreatment VF was significantly higher in the medical group.

At the study endpoint, significantly more eyes in the surgical group required additional medication(s), whereas treatment failure (requirement of surgical treatment) was significantly more frequent in the medical group.

No significant differences in the mean time between the principal intervention and requirement of further medications or operations (in the medical group), or reoperation (in the surgical group), was observed. In addition, no significant difference in the frequency of eyes with an IOP $\leq 21 \mathrm{mmHg}$ at the study endpoint was observed between the two groups (Table 1).

Trends in mean IOP, VF, BSCVA, and number of drugs before and after treatment in the two groups are shown in figure 1. According to the results of repeated measures analysis, mean IOP, VF, BSCVA, and number of drugs before and after treatment were all significantly more favorable in the surgical group at the study endpoint $(P<0.001$ for all comparisons).

Comparisons of study variables between eyes with failed and successful medical therapies are shown in table 2. Patients in the failed group were significantly younger, with a higher mean IOP, and received a greater number of drugs at baseline. In multivariate analysis, the number of drugs at baseline was the only independent predictor of medical failure ( $\mathrm{P}=0.03$; optimal cut-off point, 2 medications).
Similar comparisons between eyes with failed and successful trabeculectomies are presented in table 3. Accordingly, no significant predictor of surgical failure was identified in the present study.

\section{DISCUSSION}

In the present work, trabeculectomy was associated with significantly better outcomes in terms of changes in IOP, VF, BSCVA, and number of drugs compared to medical treatment in patients with open-angle glaucoma. Despite these favorable outcomes, the surgical and medical groups were comparable in terms of clinically desirable IOP (i.e., $\leq 21 \mathrm{mmHg}$ ) at the study endpoint.

In corroboration with these findings, Smith ${ }^{(12,13)}$ also reported more favorable IOP changes in eyes that underwent trabeculectomy compared to those that received medical therapy only. In contrast, they reported no significant differences in visual acuity or field between the two groups.

Despite considerably longer follow-up durations in the previous study by Smith (18 years), it should be noted that these studies date back to the 80's and 90's, when current cutting-edge technology, advanced surgical techniques, and patient care facilities were not available.

Similar to our findings, but in contrast with Smith's series, Jay, and Allan ${ }^{(14)}$ reported better VF changes in eyes with primary open-angle glaucoma after trabeculectomy compared to those that received conventional medical treatment at a mean follow-up of 4.6 years.

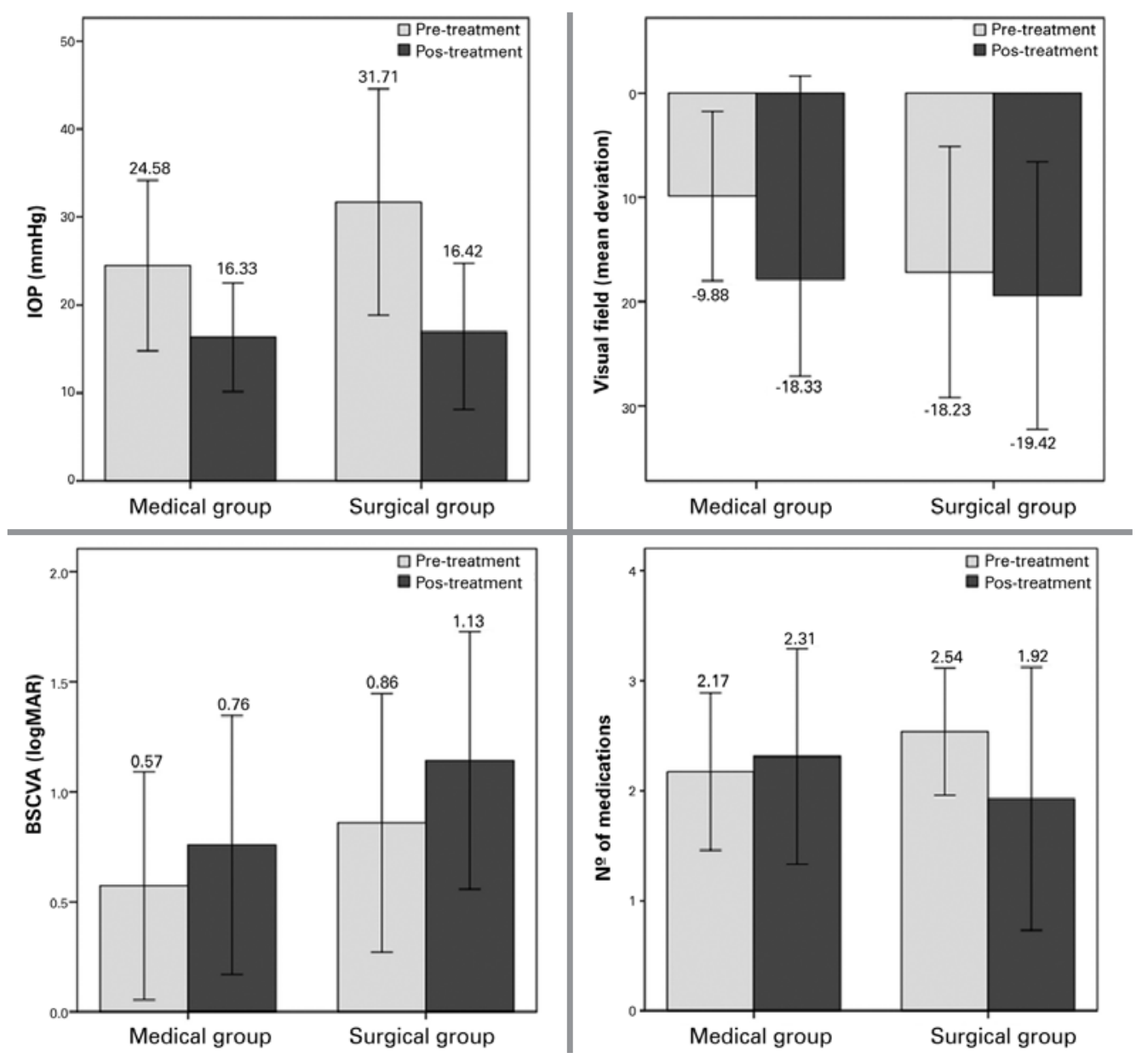

Figure 1. Change in mean intraocular pressure (IOP), visual field, best spectacle-corrected visual acuity (BSCVA), and number of drugs before and after treatment in the surgical $(n=96)$ and medical $(n=188)$ groups. Error bars represent standard deviations. 
Table 2. Comparison of study variables according to medical therapy success

\begin{tabular}{lccc}
\hline Variable & $\begin{array}{c}\text { Failed } \\
(\mathbf{n = 6 4 )}\end{array}$ & $\begin{array}{c}\text { Successful } \\
(\mathbf{n = 1 2 4 )}\end{array}$ & P-value \\
\hline $\begin{array}{l}\text { Age (year) } \\
\text { Sex }\end{array}$ & $67.11 \pm 9.63$ & $70.00 \pm 9.68$ & $0.050^{*}$ \\
$\quad$ Male & $50(78.1 \%)$ & $100(80.6 \%)$ & 0.680 \\
Female & $14(21.9 \%)$ & $24(19.4 \%)$ & \\
Glaucoma type & $1(1.6 \%)$ & $0(0 \%)$ & 0.310 \\
PIG & $42(65.6 \%)$ & $77(63.3 \%)$ & \\
PEX & $21(32.8 \%)$ & $47(37.9 \%)$ & \\
POAG & $27.46 \pm 11.50$ & $23.09 \pm 8.59$ & $0.004^{*}$ \\
Baseline IOP (mmHg) & $-9.54[2.49]$ & $-10.04[1.62]$ & 0.860 \\
Baseline VF (MD) & $0.50[0.06]$ & $0.61[0.05]$ & 0.180 \\
Baseline BSCVA (logMAR) & $2.39 \pm 0.71$ & $2.06 \pm 0.70$ & $0.003^{*}$ \\
Baseline drug no & & & \\
\hline
\end{tabular}

$\mathrm{BSCVA}=$ best spectacle-corrected visual acuity; $I \mathrm{OP}=$ intraocular pressure; $\mathrm{MD}=$ mean deviation; $\mathrm{PEX}=$ pseudoexfoliation glaucoma; $\mathrm{PIG}=$ pigmentary glaucoma; $\mathrm{POAG}=$ primary open-angle glaucoma; $\mathrm{VF}=$ visual field

P-values of $\leq 0.05$ were considered statistically significant $(*)$.

Data is presented as means \pm standard deviation (range), means [standard error of the mean] (range), or frequency (\%).

Table 3. Comparison of study variables according to failed or successful trabeculectomy

\begin{tabular}{lccc}
\hline Variable & $\begin{array}{c}\text { Failed } \\
\text { (n=11) }\end{array}$ & $\begin{array}{c}\text { Successful } \\
\text { (n=85) }\end{array}$ & P-value \\
\hline Age (year) & 67.00 & 68.00 & 0.49 \\
Sex & $8(72.8 \%)$ & $62(72.9 \%)$ & 0.62 \\
$\quad$ Male & $3(27.3 \%)$ & $23(27.1 \%)$ & \\
Female & & & \\
Glaucoma type & $3(27.3 \%)$ & $8(9.4 \%)$ & 0.10 \\
PIG & $4(36.4 \%)$ & $56(5.9 \%)$ & \\
PEX & $4(36.4 \%)$ & $21(24.7 \%)$ & \\
POAG & 23.00 & 30.00 & 0.97 \\
Baseline IOP (mmHg) & -23.00 & -24.00 & 0.57 \\
Baseline VF (MD) & 0.62 & 0.65 & 0.11 \\
Baseline BSCVA (logMAR) & 3.00 & 3.00 & 0.35 \\
Baseline drug no. & & & \\
\hline
\end{tabular}

$\mathrm{BSCVA}=$ best spectacle-corrected visual acuity; $\mathrm{IOP}=$ intraocular pressure; $\mathrm{MD}=$ mean deviation; $\mathrm{PEX}=$ pseudoexfoliation glaucoma; $\mathrm{PIG}=$ pigmentary glaucoma; $\mathrm{POAG}=$ primary open-angle glaucoma; $V F=$ visual field

P-values of $\leq 0.05$ were considered statistically significant $\left(^{*}\right)$

Data is presented as medians or frequency (\%).

Unlike in the present study, no significant difference in visual acuity changes before and after treatment was observed between surgical and medical groups.

In line with our findings in terms of VF changes, three previous trials from the UK ${ }^{(15-17)}$ compared initial medical treatment and early trabeculectomy, indicating significantly less severe deterioration of visual field with early trabeculectomy.

In a recent Cochrane study, Burr et al. ${ }^{(2)}$ reviewed the findings of four randomized controlled trials that had compared medical therapy and trabeculectomy in adults with open-angle glaucoma $(n=888)$. In corroboration with the findings of the present study, they concluded that primary trabeculectomy is superior to primary medical therapy in decreasing IOP.
Conversely, Lichter et al. ${ }^{(18)}$ found no significant differences in IOP reduction or VF deterioration between patients with open-angle glaucoma who underwent initial medical therapy or trabeculectomy at 5 years follow-up.

Despite a significant difference between the medical and surgical groups in terms of IOP changes before and after treatment in the present study, the two groups were comparable in terms of the frequency of cases with clinically desirable IOP at the study endpoint (82.3\% in the medical group vs. $87.2 \%$ in the surgical group).

Trabeculectomy reported had a success rates ranging between $48 \%$ and $98 \%$ according to previous literature ${ }^{(6,7,19-26)}$. The exact rate in eyes with medical therapy, however, is unknown. As mentioned above, there is currently a lack of sufficient data from recent studies of newer medications and surgical techniques for glaucoma ${ }^{(2)}$, with many previous reports using flawed methodologies ${ }^{(5)}$ and varying follow-up periods as well as employing different criteria to define success ${ }^{(6)}$, potentially underlying the heterogeneity in reported results.

Although the efficacy of medical therapy and trabeculectomy in achieving endpoint desirable IOP did not differ significantly in the present study, the rate of failure in the medical group, i.e., the number of cases that eventually needed trabeculectomy, was still high (34\%). In an attempt to determine potential predictors of treatment failure, we compared study variables between failed and successful medical therapy. On the basis of these findings, younger age, a higher IOP at diagnosis, and initial requirement for a greater number of pharmacological agents to control the disease were significantly associated with the failure of medical therapy. The only independent predictor, however, was the initial number of drugs (two or more).

Younger age has previously been reported as a predictor of failure of trabeculectomy ${ }^{(27)}$, but not in cases receiving medical treatments. The association between age and IOP remains controversial. Although it has been suggested that IOP increases with age in Western populations, this association may differ in other ethnic groups ${ }^{(28)}$. However, according to the univariate and multivariate models of the present study, a negative correlation between age and IOP may be plausible. Further studies evaluating this association are required.

Previous studies have posited that toxic effects of anti-glaucoma drugs, by inducing morphological changes in the conjunctiva and Tenon's capsule ${ }^{(29,30)}$, enhance the severity of local inflammation, and may increase the risk of external bleb scarring and filtration surgery failure ${ }^{(9,17,30,31)}$ and developing a significant foreshortening of the inferior fornix secondary to conjunctival fibrosis ${ }^{(32)}$.

The higher rate of failure in patients receiving medical treatments who required a greater number of initial anti-glaucoma medications in the present study may be attributable to these mechanisms. In addition, the requirement of more drugs may imply a more complicated (intractable) condition in which treatment failure may be more expected.

In the present study, we aimed to identify predictors of failure in the surgical group. However, we were unable to identify any single factor as a significant predictor of surgical failure. This finding may partly be attributable to the exclusion of cases considered high risk of treatment failure according to the presence of previously reported risk factors ${ }^{(11)}$ and the small number of cases with the failure of primary trabeculectomy included in the present study.

According to the findings of the present study, trabeculectomy was superior to medical treatment in patients with open-angle glaucoma. Although trabeculectomy may be associated with potentially vision-threatening consequences such as infection, hypotony, and over-filtration (2), these complications are reportedly very rare. An advantage of trabeculectomy over medical therapy is a reduction in issues related to pharmacological therapy duration and adherence. In addition, in many countries adequate medical therapy and close supervision are not possible in patients with glaucoma ${ }^{(16)}$. Finally, it has been shown that early trabeculectomy is more cost-effective than medical therapy. This is particularly important when resources are limited $(2,33)$ 
We acknowledge an important but inevitable limitation of the present study. The purpose of the present study was to compare therapeutic outcomes between trabeculectomy and medical treatment to decrease IOP. Ideally, the two groups to be compared should be matched in all aspects that may influence the results, such as age, sex, type, and severity of glaucoma, follow-up time, initial IOP, number of initial drugs, etc. Although we did our best to match the two groups as much as possible in this regard, differences in some important aspects, such as the type of glaucoma, initial IOP, and number of drugs, remained. Although this unavoidable limitation does not invalidate the findings of the present study, it may be considered as a compromising factor that may have adversely affected the results and conclusions. However, because the present study observed superior results in the surgical group, this limitation supports our major findings as, although more severe cases are naturally designated to the trabeculectomy group, the surgical approach demonstrated greater efficacy than conventional medical therapy in patients with open-angle glaucoma. The exclusion of patients considered high-risk patients for failure of trabeculectomy was a limitation of the present study that may have caused selection bias. This may have resulted in more favorable results in the trabeculectomy group; however, the use of a particular therapeutic approach specifically in low-risk patients may have minimized bias related to this approach. The retrospective nature of the present study was a further limitation of the present study. The findings of the present study provide a rationale for future prospective studies, particularly those designed to identify predictors of failure in medical and surgical groups and including both low-risk and high-risk patients for failure of trabeculectomy.

\section{REFERENCES}

1. Aptel F, Cucherat M, Denis P. Efficacy and tolerability of prostaglandin analogs: a meta-analysis of randomized controlled clinical trials. J Glaucoma. 2008;17(8):667-73. Comment in: J Glaucoma. 2009;18(6):498; author reply 498-9.

2. Burr J, Azuara-Blanco A, Avenell A, Tuulonen A. Medical versus surgical interventions for open angle glaucoma. Cochrane Database Syst Rev. 2012;9:CD004399.

3. Dreyer EB, Lipton SA. New perspectives on glaucoma. JAMA. 1999;281(4):306-8. Comment in: JAMA. 1999;281(23):2186-7.

4. Heijl A, Leske MC, Bengtsson B, Hyman L, Bengtsson B, Hussein M; Early Manifest Glaucoma Trial Study Group. Reduction of intraocular pressure and glaucoma progression: results from the Early Manifest Glaucoma Trial. Arch Ophthalmol. 2002;120(10):1268-79. Comment in: Arch Ophthalmol. 2002;120(10):1371-2; JAMA. 2002;288(20):2607-8. Optom Vis Sci. 2002;79(12):741-2

5. Boland MV, Ervin AM, Friedman D, Jampel H, Hawkins B, Volenweider D, et al., in Treatment for Glaucoma: Comparative Effectiveness. Rockville (MD); U.S. Department of Health and Human Services; 2012.

6. Bhatia J. Outcome of trabeculectomy surgery in primary open angle glaucoma. Oman Med J. 2008;23(2):86-9.

7. Watson PG, Grierson I. The place of trabeculectomy in the treatment of glaucoma. Ophthalmology. 1981;88(3):175-96.

8. Lavin MJ, Wormald RP, Migdal CS, Hitchings RA. The influence of prior therapy on the success of trabeculectomy. Arch Ophthalmol. 1990;108(11):1543-8.
9. Broadway DC, Grierson I, O'Brien C, Hitchings RA. Adverse effects of topical antiglaucoma medication. II. The outcome of filtration surgery. Arch Ophthalmol. 1994;112(11):1446-54. Comment in: Arch Ophthalmol. 1995;113(7):849-50.

10. Sycha T, Vass C, Findl O, Bauer P, Groke I, Schmetterer L, et al. Interventions for normal tension glaucoma. Cochrane Database Syst Rev. 2003(4):CD002222.

11. Broadway DC, Chang LP. Trabeculectomy, risk factors for failure and the preoperative state of the conjunctiva. J Glaucoma. 2001;10(3):237-49.

12. Smith RJ. Medical versus surgical therapy in glaucoma simplex. $\mathrm{Br} J$ Ophthalmol. 1972;56(3):277-83.

13. Smith RJ. The Lang lecture 1986. The enigma of primary open-angle glaucoma. Trans Ophthalmol Soc U K. 1986;105(Pt 6):618-33.

14. Jay JL, Allan D. The benefit of early trabeculectomy versus conventional management in primary open angle glaucoma relative to severity of disease. Eye (Lond). 1989;3(Pt 5): 528-35.

15. Migdal C, Gregory W, Hitchings R. Long-term functional outcome after early surgery compared with laser and medicine in open-angle glaucoma. Ophthalmology. 1994; 101(10):1651-6; discussion 7.

16. Jay JL, Murray SB. Early trabeculectomy versus conventional management in primary open angle glaucoma. Br J Ophthalmol. 1988;72(12):881-9.

17. Migdal C, Hitchings R. Control of chronic simple glaucoma with primary medical, surgical and laser treatment. Trans Ophthalmol Soc U K. 1986;105 (Pt 6):653-6.

18. Lichter PR, Musch DC, Gillespie BW, Guire KE, Janz NK, Wren PA, Mills RP; CIGTS Study Group. Interim clinical outcomes in the Collaborative Initial Glaucoma Treatment Study comparing initial treatment randomized to medications or surgery. Ophthalmology. 2001;108(11):1943-53. Comment in: Ophthalmology. 2003;110(2):249; author reply 249. Ophthalmology. 2001;108(11):1939-40. Opthalmology. 2003;110(2):250-1.

19. Jerndal T, Lundstrom M. 330 trabeculectomies--a follow-up study through 1/2-3 years. Acta Ophthalmol (Copenh). 1977;55(1):52-62.

20. D'Ermo F, Bonomi L, Doro D. A critical analysis of the long-term results of trabeculectomy. Am J Ophthalmol. 1979;88(5):829-35.

21. Mills KB. Trabeculectomy: a retrospective long-term follow-up of 444 cases. Br J Ophthalmol. 1981:65(11):790-5.

22. Akafo SK, Goulstine DB, Rosenthal AR. Long-term post trabeculectomy intraocular pressures. Acta Ophthalmol (Copenh). 1992;70(3):312-6.

23. Nouri-Mahdavi K, Brigatti L, Weitzman M, Caprioli J. Outcomes of trabeculectomy for primary open-angle glaucoma. Ophthalmology. 1995;102(12):1760-9.

24. Vesti E, Raitta C. A review of the outcome of trabeculectomy in open-angle glaucoma. Ophthalmic Surg Lasers. 1997;28(2):128-32.

25. Jacobi PC, Dietlein TS, Krieglstein GK. Primary trabeculectomy in young adults: long-term clinical results and factors influencing the outcome. Ophthalmic Surg Lasers. 1999;30(8):637-46.

26. Vesti E. Filtering blebs: follow up of trabeculectomy. Ophthalmic Surg. 1993;24(4):249-55.

27. Giaconi JA. Pearls of glaucoma management. Berlin: Springer; 2010

28. Qureshi IA. Intraocular pressure: a comparative analysis in two sexes. Clin Physiol. 1997; 17(3):247-55.

29. Sherwood MB, Grierson I, Millar L, Hitchings RA. Long-term morphologic effects of antiglaucoma drugs on the conjunctiva and Tenon's capsule in glaucomatous patients. Ophthalmology. 1989;96(3):327-35

30. Broadway DC, Grierson I, O'Brien C, Hitchings RA. Adverse effects of topical antiglaucoma medication. I. The conjunctival cell profile. Arch Ophthalmol. 1994;112(11):1437-45.

31. Abraham SV. Miotic iridocyclitis: its role in the surgical treatment of glucoma. Am J Ophthalmol. 1959;48:634-43.

32. Schwab IR, Linberg JV, Gioia VM, Benson WH, Chao GM. Foreshortening of the inferior conjunctival fornix associated with chronic glaucoma medications. Ophthalmology. 1992;99(2):197-202.

33. Ainsworth JR, Jay JL. Cost analysis of early trabeculectomy versus conventional management in primary open angle glaucoma. Eye (Lond). 1991:5(Pt 3):322-8. 